\title{
Physiological Responses of Gold Kiwifruit (Actinidia chinensis) to Reduced Irrigation
}

\author{
Tessa M. Mills \\ The New Zealand Institute of Plant and Food Research, Private Bag 11600, Palmerston North 4442, \\ New Zealand \\ Jianming Li \\ College of Horticulture, Northwest A\&F University, Yangling, China \\ M. Hossein Behboudian ${ }^{1}$ \\ Institute of Natural Resources (INR 433), Massey University, Palmerston North, New Zealand
}

\begin{abstract}
AdDitional Index words. discrimination against ${ }^{13} \mathrm{CO}_{2}$, photosynthesis, plant water use, stomatal conductance
Abstract. Information on water relations and water stress physiology of Actinidia chinensis Planch. is scant. We aimed at providing such information by exposing potted 1-year-old plants to reduced irrigation in a glasshouse. The treatments were control (C) receiving sufficient water to replace $100 \%$ of evapotranspiration, early (E) reduced irrigation for 13 days earlier in the experiment, late $(L)$ reduced irrigation for 13 days later in the experiment, and recovery $(R)$ undergoing $E$ and $L$ with 5 days of full irrigation in between to recover from $E$. All plants were fully watered between early and late episodes of reduced irrigation. Soil volumetric water content was lower in $\mathrm{E}$, $\mathrm{L}$, and $\mathrm{R}$ compared with $\mathrm{C}$, leading to lower leaf water potential, photosynthetic rate (Pn), and stomatal conductance $\left(g_{s}\right)$. Pn was lower in the reduced irrigation vines only when $\mathrm{g}_{\mathrm{s}}$ was below $0.1 \mathrm{~mol} \cdot \mathrm{m}^{-2} \cdot \mathrm{s}^{-1}$. High leaf temperature in the glasshouse imposed nonstomatal limitations to photosynthesis as indicated by elevated internal leaf $\mathrm{CO}_{2}$ concentrations $\left(C_{i}\right)$. Following rewatering, the stressed vines showed rapid recovery of leaf water potential and photosynthesis. However, $C_{i}$ and $g_{s}$ were slower to respond. There was an indication of osmotic adjustment in leaves under reduced irrigation. Discrimination against ${ }^{13} \mathrm{CO}_{2}$ was the same among the treatments. A. chinensis had better stomatal control under water stress compared with Actinidia deliciosa, for which some information is available. Water stress history in $A$. chinensis encouraged more drought resistance in the subsequent water stress period, but this was not sustained. Although field performance of $A$. chinensis under water stress is expected to be better than what we have presented here, long periods of deficit irrigation for this species cannot be recommended.
\end{abstract}

Kiwifruit (Actinidia deliciosa and A. chinensis) is an important commercial crop in New Zealand and is grown primarily in the Bay of Plenty but spreads from Kerikeri in the north to Nelson in the south. Irrigation is often necessary due to unreliable rainfall, soils with poor water holding capacity, and root growth limitations. Kiwifruit is native to the mountains of southern China and has evolved in a high humidity area with regular annual rainfall of 1050 to $1950 \mathrm{~mm}$ (Buwalda and Smith, 1990). These authors found that green kiwifruit (A. deliciosa var. deliciosa 'Hayward') has a high transpiration rate with poor stomatal control. Green et al. (1989) reported that A. deliciosa transpires at night and this could account for up to $30 \%$ of all the water used for any given $24-\mathrm{h}$ period. However, Gucci et al. (1997) reported that A. deliciosa does not demonstrate low midday leaf water potential values under water deficit as effective stomatal closure allows water conservation. But Chartzoulakis et al. (1993) reported that A. deliciosa seedlings showed poor control of transpiration even though there was a reduction in stomatal conductance $\left(\mathrm{g}_{\mathrm{s}}\right)$ and suggested that this species has poor epidermal control of water loss through leaky stomata or an insufficient cutinisation of the epidermis.

Conflicting reports on the ability of kiwifruit to reduce water loss under water deficit warranted investigation. Most of the

Received for publication 10 Sept. 2009. Accepted for publication 30 Nov. 2009. ${ }^{1}$ Corresponding author. E-mail: M.Behboudian@massey.ac.nz. information on the water relations of kiwifruit relates to $A$. deliciosa (e.g., Judd et al., 1989; Miller et al., 1998; Reid et al., 1996). We were interested in obtaining information on the water stress physiology of gold kiwifruit (A. chinensis Planch. var. chinensis 'HORT16A') as it has been extensively planted in recent years on many sites in New Zealand where soil water holding capacity is low, rainfall is variable, and periodic soil water deficits may develop.

Gold kiwifruit differs from green in that its dormancy break is $\approx 1$ month earlier, and tends to have a higher crop load and a higher percentage of dry matter (DM) in the fruit. It is harvested earlier than green kiwifruit by up to 6 weeks. The higher fruit DM gives gold kiwifruit a better taste.

We studied the impact of reduced irrigation on pot-grown $A$. chinensis with specific interest in its physiological responses in terms of water relations, gas exchange parameters, and growth. Our experimental design provided the opportunity of studying the effect of water stress history on plant physiological responses to water stress that are sometimes difficult to establish in the field. We wished to test the hypothesis that kiwifruit demonstrates physiological adaptation to water stress following a previous stress episode.

\section{Materials and Methods}

Plant materials and Cultural conditions. This research was carried out at the Plant Growth Unit, Massey University, 
Palmerston North, New Zealand (lat. $40^{\circ} 23^{\prime}$ S, long. $175^{\circ} 37^{\prime} \mathrm{E}$ ) during Summer of 2007. Bare-rooted seedling vines of gold kiwifruit were purchased from a Te Puke, New Zealand nursery in Sept. 2006 and were initially planted into 10-L plastic pots containing a bark-based potting mixture and 3-month slowrelease fertilizer (Osmocote; Scotts, Marysville, OH). Plants were then repotted on 19 Dec. 2006 into 30-L plastic pots (diameter $300 \mathrm{~mm}$ ) containing a soil mixture of fine sandy loam (two-thirds) and coarse sand (one-third). Six-month slowrelease fertilizer (Osmocote) was incorporated into the soil mixture at the time of repotting. Vines were supported within the pot by a 1-m aluminum L-shaped frame that was secured on the inside base of the pot. Between repotting in Dec. 2006 and experimental work commencing in Feb. 2007, vines were pruned and trained to encourage strong vegetative growth and were kept well watered in an outside standing area. On 12 Feb. 2007, vines were moved to a glasshouse and spaced at $\approx 1 \times 1 \mathrm{~m}$ before evapotranspiration (ET) was subsequently measured over a $24-\mathrm{h}$ period for each vine. To do this, individual pots were first watered to pot capacity by watering to excess and allowing drainage to occur. Vine weight was then determined using a balance (EB 60; August Sauter, Ebingen, Germany or Albstadt KB 60.2; Mettler-Toledo, Zürich, Switzerland). After $24 \mathrm{~h}$ with no additional water added, pot weights were again measured and the weight difference was assumed to be water lost through ET. The ET measured for each pot was the basis for applying irrigation treatment to the pot.

Treatments. Four treatments were randomly assigned to 24 pots (six pots per treatment) on 16 Feb. 2007. Sixteen more pots surrounded the experimental pots as buffers against any edge effect within the glasshouse. The four treatments were control (C), receiving sufficient water to replace $100 \%$ of ET; early (E) reduced irrigation for the first $13 \mathrm{~d}$ of stress period (Phase 1); late $(\mathrm{L})$ reduced irrigation during the last $13 \mathrm{~d}$ of stress period (Phase 2); and recovery (R) undergoing $\mathrm{E}$ and $\mathrm{L}$ with $5 \mathrm{~d}$ of full irrigation between Phases 1 and 2 to recover from E. Following Phase 2, 2 or $3 \mathrm{~d}$ of recovery measurements were made. All plants were fully watered between Phase 1 and Phase 2. The E vines were irrigated with $70 \%$ of ET for the first $6 \mathrm{~d}$ in Phase 1 and then with $50 \%$ of measured ET for the next $7 \mathrm{~d}$. This was the same for $\mathrm{R}$. E and $\mathrm{R}$ received the same treatment in Phase 1; therefore, they are used interchangeably in our data presentation for that phase. L was irrigated with $50 \%$ of measured ET during the first $7 \mathrm{~d}$ of Phase 2 and then with $40 \%$ of measured ET during the next $6 \mathrm{~d}$. This was the same for R. Although R and $\mathrm{L}$ had the same treatment in Phase 2, $\mathrm{R}$ had a previous water stress history that $\mathrm{L}$ did not have. Amounts of water applied during the $13 \mathrm{~d}$ of Phase 1 were 26.9, 15.9, 25.1, and 12.9 $\mathrm{L}$ for $\mathrm{C}, \mathrm{E}, \mathrm{L}$, and $\mathrm{R}$, respectively. The corresponding values for Phase 2 were 26.9, 26.7, 11.3, and 9.9 L. Our results are mostly presented on the basis of day of experiment (DOE). The day ET was measured was considered as DOE 0 . The other measurements started on DOE 2. Phase 1 was finished on DOE 14, rewatering was done from DOE 14 to 19, and Phase 2 was from DOE 19 to 32 . Up to $3 \mathrm{~d}$ of measurements were made after rewatering of plants at the end of Phase 2. The experiment therefore lasted for $35 \mathrm{~d}$.

Water Relations. Plant-water relation measurements were made on the youngest fully expanded leaves on each vine throughout the experimental period. Midday leaf water potential $\left(\psi_{1}\right)$ was measured using a Scholander pressure chamber (Soil Moisture Equipment, Santa Barbara, CA). Leaf water potential and leaf osmotic potential $\left(\psi_{\mathrm{s}}\right)$ were also measured employing a psychrometer-hygrometer using C-52 sample chambers in conjunction with an HR-33T microvoltmeter (Wescor, Logan UT) as detailed by Mills et al. (1997). Results obtained for $\psi_{1}$ using the psychrometer-hygrometer were not consistent, possibly due to the thick leaf cuticle typical of kiwifruit. Leaf $\psi_{\mathrm{S}}$ values, in contrast, were consistent and reproducible. Relative water content (RWC) was determined using the method of Barrs and Weatherley (1962) on fully mature leaves. Leaf disks of 10-mm diameter were taken at the same time as pressure chamber determinations of $\psi_{1}$.

Leaf gas exchange. Photosynthetic rate $(\mathrm{Pn}), \mathrm{g}_{\mathrm{s}}$, internal leaf $\mathrm{CO}_{2}$ concentrations $\left(\mathrm{C}_{\mathrm{i}}\right)$, and leaf temperature were determined on young but fully expanded leaves using a photosynthesis measurement system (LI-6400; LI-COR, Lincoln, NE). Photosynthetically active radiation $(P A R)$ was maintained at $1000 \mu \mathrm{mol} \cdot \mathrm{m}^{-2} \cdot \mathrm{s}^{-1}$ using a red-blue light source within the closed leaf chamber. The $\mathrm{CO}_{2}$ concentration within the leaf chamber was maintained at $400 \mu \mathrm{L} \cdot \mathrm{L}^{-1}$ during the measurements. Concomitantly with $\psi_{1}$ measurements, light response curves were determined periodically throughout Phase 2 on $\mathrm{C}$ and $\mathrm{R}$ plants. Irradiance levels ranged from 0 to 1300 $\mu \mathrm{mol} \cdot \mathrm{m}^{-2} \cdot \mathrm{s}^{-1}$, while chamber $\mathrm{CO}_{2}$ concentrations and humidity were retained at $400 \mu \mathrm{L} \cdot \mathrm{L}^{-1}$ and between $40 \%$ and $50 \%$, respectively. Discrimination against ${ }^{13} \mathrm{CO}_{2}$ was measured for $\mathrm{C}$ and $\mathrm{R}$ by taking leaf samples on DOE 1 and 32 . The youngest fully mature leaves were sampled for the purpose. Leaves sampled at DOE 32 had been actively growing during the stress period. The sampled leaves were dried and ground to a fine powder before being sent to an accredited laboratory for stable isotope analysis (University of Waikato, Hamilton, New Zealand). ${ }^{13} \mathrm{C}$ determinations were carried out using a Dumas Elemental Analyzer (Europa Scientific, Crewe, UK) interfaced to a stable isotope mass spectrometer (Tracemass, Europa Scientific). Further description of ${ }^{13} \mathrm{CO}_{2}$ discrimination is outlined in Mills et al. (1998).

SoIL WATER CONTENT. Soil volumetric water content $(\theta)$ was determined periodically throughout the experiment using time domain reflectometry (TDR model 6050X3K1, MiniTrase Kit; Soil Moisture Equipment) with 200-mm wave guides. Radiation data within the glasshouse were recorded throughout the experiment using a quantum sensor (LI-1900; LI-COR) and temperature and humidity were measured using a humitter (PY50; Vaisala Oyi, Helsinki, Finland) within a radiation screen. Meteorological data were recorded hourly with a datalogger (XR10; Campbell Scientific, Logan, UT). Within the glasshouse over the experimental period, midday air temperature, relative humidity, and vapor pressure deficit ranged between 16.7 and $35.9{ }^{\circ} \mathrm{C}, 25.3 \%$ and $93.6 \%$, and 0.123 and $4.43 \mathrm{kPa}$, respectively. Daily midday air temperature and relative humidity values are presented in Fig. 1.

Plant water use. During Phase 2, total plant water use was recorded for six vines, two from each of C, L, and R, using 100kg load cells (AG100; Scaime, Annemasse, France) mounted between two aluminum plates, each having an area of $0.4 \mathrm{~m}^{2}$ and a thickness of $6 \mathrm{~mm}$. The pot weight was recorded every hour. The change in pot weight minus any measured water added as irrigation gives the total evapotranspiration from the pot and vine for each $24-\mathrm{h}$ period. The soil surface within the pots was not covered. Therefore, a small amount of water loss will have occurred from the soil surface following irrigation. These data coupled with the estimated leaf area made it possible 


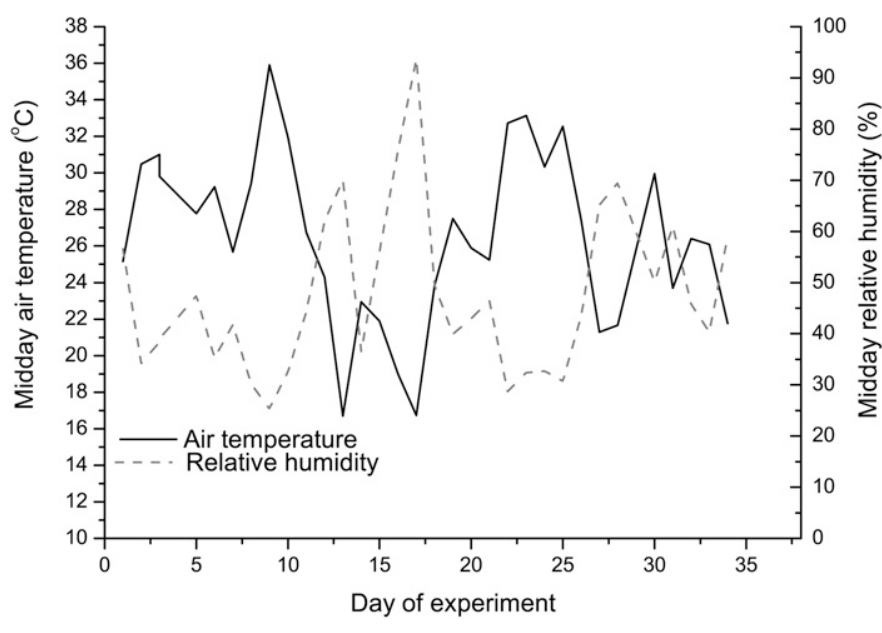

Fig. 1. Midday air temperature and relative humidity in the glasshouse where vines of Actinidia chinensis were grown and exposed to reduced irrigation.

to express water use per unit leaf area per day. Leaf area was estimated by measuring the average area of single leaves on the guard plants. This was done by destructive measurement of all leaves using a leaf area meter (LI-3100; LI-COR), and then multiplying this average by the number of leaves on the experimental plants.

Growth Determinations. Growth was measured every 2 to $3 \mathrm{~d}$ on four tagged leaves per treatment. These leaves were on nonterminating shoots and were $\approx 10$ to $20 \mathrm{~mm}$ wide at the beginning of measurements. Here, nonterminating shoots describe shoots arising on the kiwifruit vine that will continue to grow throughout the growing season. Ending shoots as used in this article describe shoots that are less vigorous, have smaller leaves and shorter internodes, and cease growth during the growing season. The percentage of ending shoots was recorded for each vine within each of the four treatments at the end of Phase 2.

DAta Analysis. Statistical analysis was performed using mean and standard error functions, analysis of variance, and calculations of least significant difference (LSD) options within Excel (Microsoft, Redmond, WA).

\section{Results}

Figure 2 presents changes in $\theta, \psi_{1}$, and $\psi_{\mathrm{s}}$ for Phases 1 and 2 of reduced irrigation. The $\theta$ for $\mathrm{C}$ declined at the beginning of the experiment because of under-watering, which was redressed in subsequent irrigations. There was evidence of hysteresis for this soil mixture because $\theta$ in the previously reduced irrigated pots did not recover to that of $\mathrm{C}$ the day after rewatering (Fig. 2A). The differences in $\theta$ between $\mathrm{C}$ and reduced irrigation vines were reflected in similar trends in $\psi_{1}$ (Fig. 2B). Once Phase 1 was complete and $E$ vines, six of which became $\mathrm{R}$ vines in Phase 2 , were rewatered, $\psi_{1}$ recovered rapidly to the values in $\mathrm{C}$ vines within $24 \mathrm{~h}$ (Fig. 2B). There were also significant differences in $\psi_{\mathrm{s}}$ between $\mathrm{C}$ and $\mathrm{R}(=\mathrm{E})$ late in Phase 1 (Fig. 2C). It was only late in Phase 2 that a significant difference existed in leaf RWC among the treatments. On DOE 32, the RWC values were $92.09 \% \pm 1.09 \%, 88.23 \% \pm 0.75 \%$, and $86.92 \% \pm 0.89 \%$ for $\mathrm{C}, \mathrm{L}$, and $\mathrm{R}$, respectively.

$\mathrm{Pn}$ and $\mathrm{g}_{\mathrm{s}}$ were significantly higher in $\mathrm{C}$ than in the reduced irrigation plants (Fig. 3, A and B) from the middle of Phase 1

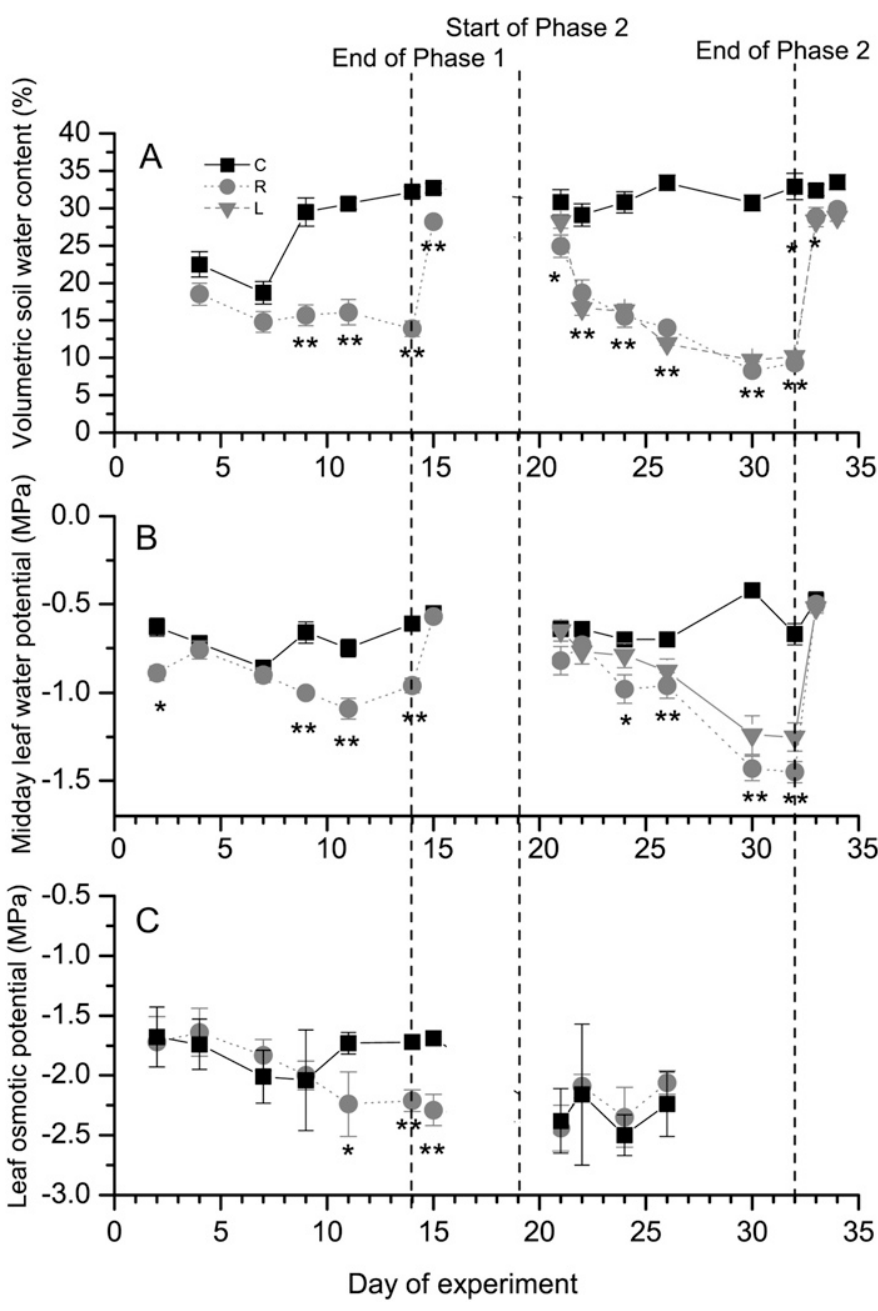

Fig. 2. Soil volumetric water content (A), midday leaf water potential (B), and leaf $\psi_{\mathrm{S}}(\mathbf{C})$ in Phases 1 and 2 of reduced irrigation in Actinidia chinensis. $\mathrm{C}=$ control, $\mathrm{E}=$ reduced irrigation in Phase $1, \mathrm{R}=$ reduced irrigation in Phases 1 and $2, \mathrm{~L}=$ reduced irrigation in Phase $2, \mathrm{R}=\mathrm{E}$ for Phase 1 . Values are means \pm SE; An asterisk indicates $P<0.05$ and $* *$ indicates $P<0.01$.

and Phase 2. Pn was reduced in all plants during Phase 2 and $\mathrm{C}_{\mathrm{i}}$ showed an increase compared with Phase 1 . This may be due to plant aging as Phase 2 coincided with later part of the growing season in New Zealand. The general reduction in $\mathrm{C}_{\mathrm{i}}$ in $\mathrm{R}$ compared with $\mathrm{C}$ also indicates stomatal closure in $\mathrm{R}$ (Fig. $3 C)$. However, late in Phase 2, an increase in $C_{i}$ for $R$ was observed. This overlapped with R's lowest RWC value of $86.92 \%$ on DOE 32 and lowest $\psi_{1}$ (Fig. 2B). The continued higher $\mathrm{C}_{\mathrm{i}}$ might be a cause of lower $\mathrm{g}_{\mathrm{s}}$ as stomata close if $\mathrm{CO}_{2}$ levels are high in the atmosphere and also within the leaf (Bunce, 2007).

Our experimental period coincided with a hot February in the New Zealand summer (Fig. 1). At times, leaf temperatures exceeded $30{ }^{\circ} \mathrm{C}$ during the midday photosynthetic measurements in the glasshouse (Fig. 3D). Leaf temperatures tended to be higher in $\mathrm{R}$ than in $\mathrm{C}$ for Phases 1 and 2, but differences were not significant during Phase 2 (Fig. 3D). Visible leaf damage due to excessive leaf heating did not occur in any of the experimental vines. Values of Pn showed recovery within $24 \mathrm{~h}$ of rewatering (Fig. $3 \mathrm{~A}$ ). However, $\mathrm{g}_{\mathrm{s}}$ and $\mathrm{C}_{\mathrm{i}}$ took longer to recover after rewatering (Fig. 3, B and C). Lower $\mathrm{g}_{\mathrm{s}}$ values 

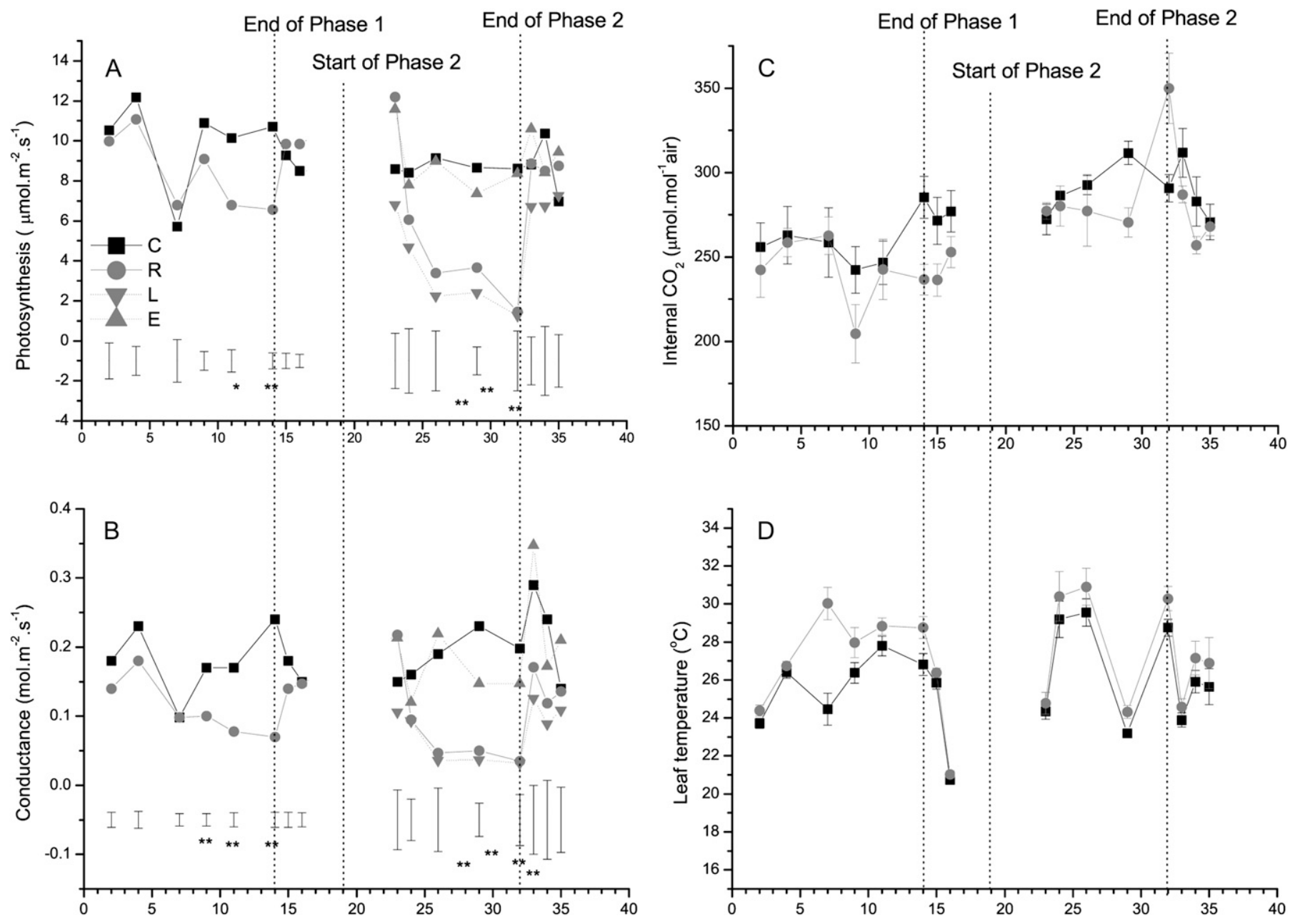

Day of experiment

Fig. 3. Photosynthetic rate $(\mathbf{A}), g_{\mathrm{S}}(\mathbf{B})$, internal $\mathrm{CO}_{2}$ concentration $(\mathbf{C})$, and leaf temperature $(\mathbf{D})$ in Phases 1 and 2 of reduced irrigation in Actinidia chinensis. $\mathrm{C}=$ control, $\mathrm{E}=$ reduced irrigation in Phase $1, \mathrm{R}=$ reduced irrigation in Phases 1 and $2, \mathrm{~L}=$ reduced irrigation in Phase 2, $\mathrm{R}=\mathrm{E}$ for Phase 1 . Separate bars represent LSD; * indicates $P<0.05$ and ** indicates $P<0.01$. Only $\mathrm{C}$ and $\mathrm{R}$ are shown in Panels $\mathrm{C}$ and $\mathrm{D}$. Values are means with $\pm \mathrm{SE}$ to indicate significance.

during Phase 2 in $\mathrm{R}$ and $\mathrm{L}$ vines are coupled with lower Pn compared with the $\mathrm{C}$ vines.

During $\mathrm{CO}_{2}$ fixation, plants discriminate against naturally occurring ${ }^{13} \mathrm{CO}_{2}$. The level of discrimination provides an integrated measure of physiological performance of the plant between sampling periods (Farquhar et al., 1989). Our data showed that in $A$. chinensis exposed to water stress, there was no reduction in ${ }^{13} \mathrm{CO}_{2}$ discrimination despite reductions in $\mathrm{Pn}$ and $\mathrm{g}_{\mathrm{s}}$ over the same period. The $\delta^{13} \mathrm{C}$ values $(\% \pm \mathrm{SE})$ at DOE 1 were $-27.75 \pm 1.01$ and $-27.10 \pm 0.46$ for $\mathrm{C}$ and for $\mathrm{R}$, respectively. The corresponding values at DOE 32 were $-28.46 \pm 0.38$ and $-28.03 \pm 0.36$.

Pn was measured at different levels of $P A R$ for $\mathrm{R}$ and $\mathrm{C}$ leaves (two replicates for each treatment) in Phase 2 and following rewatering (Fig. 4). For $\mathrm{C}$ vines, Pn leveled out at $P A R$ values of 500 to $600 \mu \mathrm{mol} \cdot \mathrm{m}^{-2} \cdot \mathrm{s}^{-1}$, suggesting that these leaves reached $P A R$ saturation. $\mathrm{R}$ vines had a lower maximum Pn rate and this was saturated at $P A R$ levels of $\approx 200$ $\mu \mathrm{mol} \cdot \mathrm{m}^{-2} \cdot \mathrm{s}^{-1}$. The $\mathrm{Pn}$ of $\mathrm{C}$ vines saturated at a lower irradiance compared with the $800 \mu \mathrm{mol} \cdot \mathrm{m}^{-2} \cdot \mathrm{s}^{-1}$ for well watered $A$. deliciosa vines reported by Chartzoulakis et al. (1993). Data presented here do show variance between measurement days and between leaves within the same treatment. More data are needed for confirmation of these results. Lower Pn in $\mathrm{R}$ vines was associated with decreased values of $g_{s}$ and $C_{i}$ (Fig. 3, B and C). By DOE 28, Phase 2 was well established and $\mathrm{R}$ vines were showing reduced $\psi_{1}$. At this date elevated $C_{i}$ levels were apparent in $\mathrm{R}$ vines (Fig. 4F). Upon rewatering at DOE 32, Pn showed recovery, but $g_{s}$ and $C_{i}$ were still reduced at DOE 35 (Fig. 4, $\mathrm{H}$ and I).

$\mathrm{R}$ and $\mathrm{E}$ vines were receiving reduced irrigation in Phase 1, but their leaf growth tended to be higher than that of $\mathrm{C}$ for the first few days of Phase 1 (Fig. 5A). However, late in Phase 1 and with the start of Phase 2 (from DOE 19 in Fig. 5A), C and E had the same leaf area, as $\mathrm{E}$ was being fully watered and leaf growth continued, and both tended to have higher leaf growth than that of $\mathrm{L}$ and R. For Phase 2, a new set of expanding leaves were measured (Fig. 5B). Leaf growth in L, which was under reduced irrigation for the first time, was less than the other treatments, including R. A leveling off in leaf growth illustrated in Fig. 5A demonstrates that leaves were reaching full expansion. Overall, Fig. 5 shows the sensitivity of leaf growth to reduced irrigation applied at any stage, including for $\mathrm{C}$ vines that were underwatered at the beginning of Phase 1. It also demonstrates 

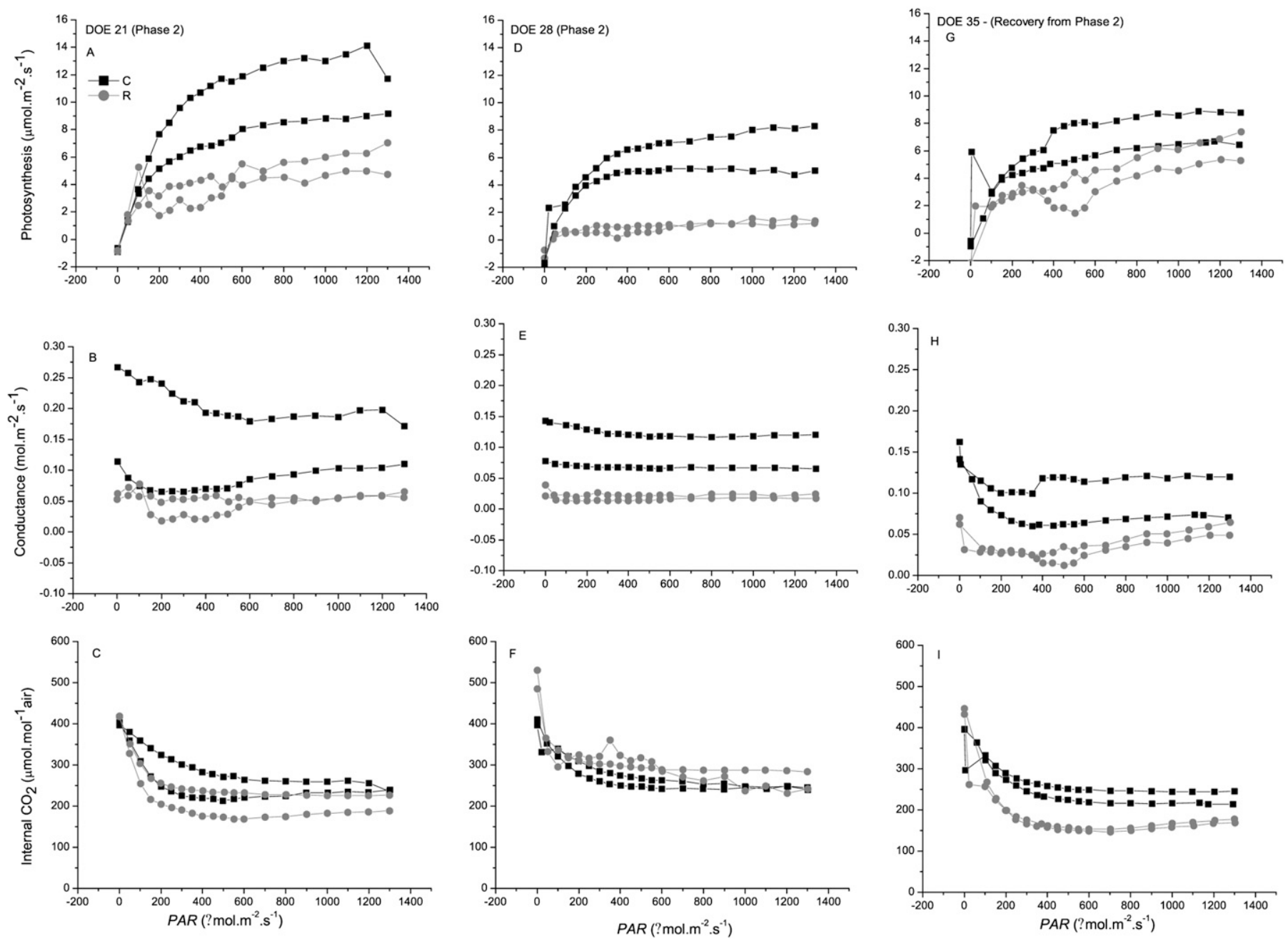

Fig. 4. Light response curves in Phase 2 of reduced irrigation for Actinidia chinensis. $\mathrm{C}=$ control, $\mathrm{R}=$ reduced irrigation in Phases 1 and 2. (A-C) Photosynthetic rate, $g_{\mathrm{S}}$, and internal $\mathrm{CO}_{2}$ concentration $3 \mathrm{~d}$ into Phase 2, respectively; (D-F) These values $9 \mathrm{~d}$ into Phase 2; (G-I) These values $3 \mathrm{~d}$ after rewatering.

that a history of water stress helped maintain this growth (Fig. 5B). Shoot growth in A. chinensis is initiated throughout the season, with some shoots becoming ended while others are nonterminating. At DOE 35, the percentages of ending shoots were $29,30,65$, and 68 for $\mathrm{C}, \mathrm{E}, \mathrm{L}$, and R, respectively. Chartzoulakis et al. (1993) found that 'Hayward' kiwifruit partitioned more photosynthates into roots under water stress than into shoots. This might have happened in our experiment, resulting in a higher ending shoots in $\mathrm{L}$ and $\mathrm{R}$ than in $\mathrm{C}$ vines. However, we do not have root growth data to substantiate this.

Mean daily plant water use differed among treatments in Phase 2 (Fig. 6). $\mathrm{R}$ had a higher water use than $\mathrm{L}$, but lower than that of C. Upon rewatering at the end of Phase 2, R showed more rapid recovery than L. Photosynthetic rate was also higher in R than in L (Fig. 3A) for the same days that total water use was higher (Fig. 6).

\section{Discussion}

A reduction in $\theta$ was accompanied by an expected reduction in $\psi_{1}$ in the reduced irrigation vines. Late in Phase 1, there was also a significant difference in $\psi_{\mathrm{s}}$ between $\mathrm{C}$ and R (Fig. 2C).
This is indicative of osmotic adjustment that has been reported for $A$. deliciosa (Chartzoulakis et al., 1997) when water deficit was imposed for longer than $10 \mathrm{~d}$. No literature reports for $A$. chinensis are available for comparison and confirmation of osmotic adjustment. Measurements of RWC did not show differences between treatments until late in Phase 2, which indicates that for the $\mathrm{R}$ vines, the water stress history (of Phase 1) was not advantageous in maintaining higher RWC than for $\mathrm{L}$ vines, which were undergoing reduced irrigation for the first time. We might expect that if $\psi_{\mathrm{s}}$ was adjusted in Phase 1, then RWC would also show treatment effects at this time. The difference in RWC late in Phase 2 is also reflected in a similar difference in $\psi_{1}$ at DOE 32 (Fig. 2B).

Stomatal conductance responded more rapidly (judged by significant differences indicated in Fig. 3) to reduced irrigation than did photosynthetic rate, suggesting that $\mathrm{Pn}$ was not limited by $g_{s}$ until $g_{s}$ values dropped to below $\approx 0.1 \mathrm{~mol} \cdot \mathrm{m}^{-2} \cdot \mathrm{s}^{-1}$. This was observed in Phases 1 and 2. It is likely that stomatal closure was the primary cause of reduced photosynthesis. It has been stated that kiwifruit has poor stomatal control (Buwalda and Smith, 1990; Judd et al., 1989), but this does not seem to apply here. Our results support the finding of Chartzoulakis et al. (1997) and Gucci et al. (1993) for A. deliciosa, as 


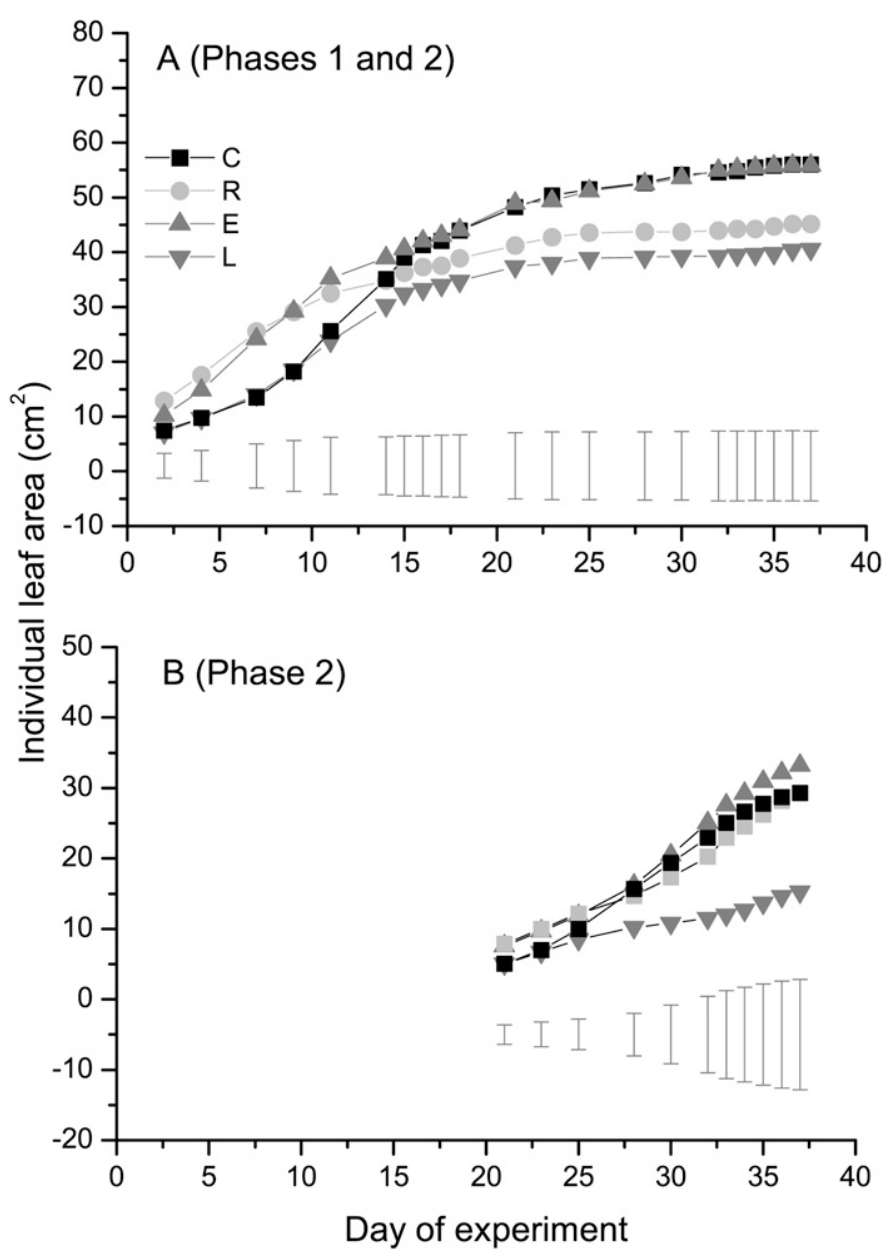

Fig. 5. Mean area of four leaves per treatment measured every few days during Phases 1 and 2 of reduced irrigation for Actinidia chinensis; $\mathrm{C}=$ control, $\mathrm{E}=$ reduced irrigation in Phase $1, \mathrm{R}=$ reduced irrigation in Phases 1 and $2, \mathrm{~L}=$ reduced irrigation in Phase 2. Vertical bars represent \pm pooled SE at each measurement date.

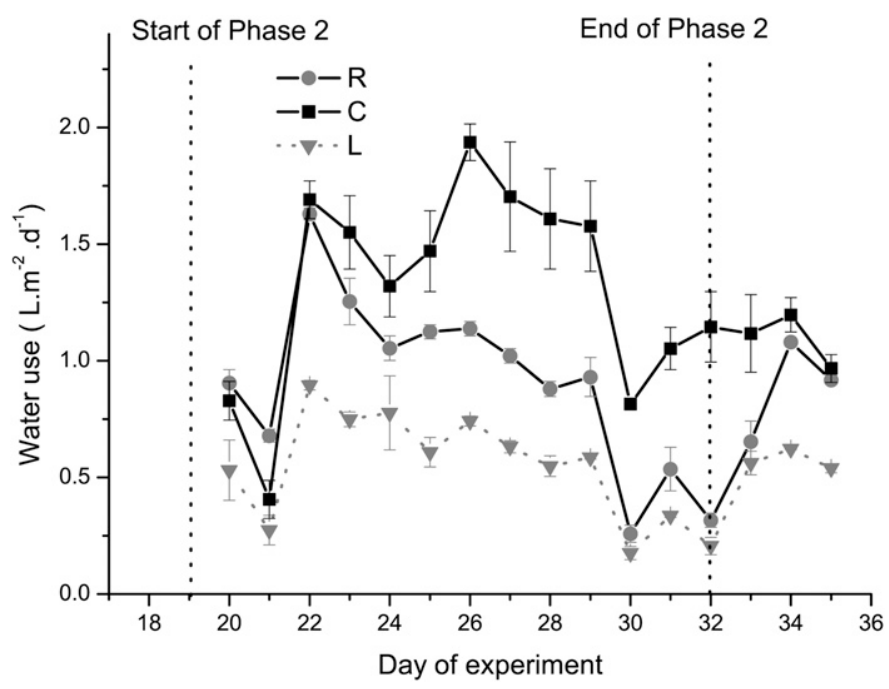

Fig. 6. Whole-plant water use, on daily basis per unit leaf area, in Phase 2 of reduced irrigation in Actinidia chinensis; $\mathrm{C}=$ control, $\mathrm{R}=$ reduced irrigation in Phases 1 and 2, $\mathrm{L}=$ reduced irrigation in Phase 2 . significant stomatal closure occurred (Fig. 3B) with decreases in $\psi_{1}$ (Fig. 2B). Late in Phase 2, an increase in $\mathrm{C}_{\mathrm{i}}$ for $\mathrm{R}$ vines when compared with earlier measures of $C_{i}$ during Phase 2 was observed and is indicative of impaired photosynthetic performance after undergoing two phases of water stress. Alternatively, elevated $C_{i}$ will reduce $g_{s}$, demonstrating acclimation of these vines to water stress. This overlapped with R's lowest RWC value of $86.92 \%$ on DOE 32 and lowest $\psi_{1}$ (Fig. 2B).

Chartzoulakis et al. (1993) showed that at leaf temperatures above $25{ }^{\circ} \mathrm{C}$, some limitation to Pn occurred in A. deliciosa. Higher leaf temperatures in $\mathrm{C}$ and $\mathrm{R}$ vines during Phase 2 may account for the overall reduction in Pn compared with Phase 1 in both treatments. The observed reduction in $\mathrm{Pn}$ in the $\mathrm{C}$ vines during Phase 2 was not coupled with reduced $\mathrm{g}_{\mathrm{s}}$. This may also suggest that Pn limitation was due to a disruption in photosynthetic mechanisms under elevated leaf temperature. Lakso (1990) suggested that the large round leaves of kiwifruit do not exchange heat efficiently with the bulk air unless there is significant air movement and are likely to have significant temperature increases under reduced $g_{s}$. Gucci et al. (1997) estimated that under moderate water stress, kiwifruit vines may have leaf temperatures of $2.5^{\circ} \mathrm{C}$ higher than well-watered vines and this difference could be 5 to $6^{\circ} \mathrm{C}$ under severe water stress. Compared with their Phase 1 values, Pn rate of the $\mathrm{C}$ vines was also reduced possibly because of high leaf temperatures in Phase 2 (DOE 20-32; Fig. 3D) and also because of leaf aging (Kitajima et al., 1997).

The sensitivity of kiwifruit to leaf temperature and the consequent reduction in photosynthesis has important implications for their field management. Irrigation water could be used to cool the canopy and thus avoid leaf heating and potentially leaf damage, including necrosis (Gucci et al., 1997).

A decrease in $C_{i}$ in $R$ vines (Fig. 3C) may indicate that $g_{s}$ was reduced more rapidly than $\mathrm{Pn}$. We would therefore have expected a difference in ${ }^{13} \mathrm{CO}_{2}$ discrimination. However, there was a tendency for less negative values of $\delta^{13} \mathrm{C}$ in $\mathrm{R}$ vines on DOE 32. Each of the two stress periods, with full watering in between, might have been too brief to develop a significant difference in $\delta^{13} \mathrm{C}$ values between $\mathrm{C}$ and $\mathrm{R}$. Leaves sampled at DOE 32 had completed some of their growth during Phase 1 and Phase 2, but despite this, no difference was observed between treatments. By DOE 28, Phase 2 was well established and $R$ vines were showing reduced $\psi_{1}$. At this date, elevated $C_{i}$ levels were apparent in $\mathrm{R}$ vines from measurements of $\mathrm{Pn}$ at different $P A R$ levels (Fig. 4F). This may indicate a reduction in Pn potential and could be considered as a form of acclimation to match the reduction in $g_{\mathrm{S}}$.

Upon rewatering at DOE 32, Pn showed recovery, but $\mathrm{g}_{\mathrm{s}}$ and $\mathrm{C}_{\mathrm{i}}$ were still reduced at DOE 35 (Fig. 4). These data support those presented in Fig. 3. They also confirm the longestablished observation that hydraulically based parameters, such as $\psi_{1}$, recover sooner (Fig. 2) than biochemically based parameters such as $g_{s}$ (e.g., Hsiao, 1973), although $g_{s}$ is also controlled by $\psi_{1}$. The data also demonstrate that stomatal and nonstomatal limitations to $\mathrm{Pn}$ occur in kiwifruit and that although $\psi_{1}$ and $\mathrm{Pn}$ recover quickly, $\mathrm{g}_{\mathrm{s}}$ is reduced and $\mathrm{C}_{\mathrm{i}}$ remains low after rewatering of previously water-stressed vines. With the regulation of leaf temperature being dependent on leaf transpiration, the reduced $g_{s}$ of the previously stressed vines may increase the likelihood of temperature stress developing in previously water-stressed leaves. 
$\mathrm{R}$ and $\mathrm{E}$ vines were receiving reduced irrigation in Phase 1, but their leaf growth was higher than that of $\mathrm{C}$ for the first few days of Phase 1 (Fig. 5A). The retention of growth rate in $\mathrm{R}$ and $E$ vines early in the reduced irrigation period also corresponded with maintenance of $\psi_{1}$ and Pn at similar levels to $\mathrm{C}$ during this period. At the beginning of Phase 1, C was underwatered, resulting in similar values of $\theta$ with that of $R$, which is equal to E during Phase 1. With the start of Phase 2 (from DOE 19 in Fig. 5A), $\mathrm{C}$ and $\mathrm{E}$ had the same leaf growth, as $\mathrm{E}$ was being fully watered, and $\mathrm{C}$ and $\mathrm{E}$ had higher growth rates than $\mathrm{L}$ or $\mathrm{R}$. During Phase 2, a new set of leaves was measured for expansion growth and leaf areas of $\mathrm{L}$, which were under reduced irrigation for the first time, were less than the other treatments (Fig. 5B). This is interesting considering that $\mathrm{R}$ was also being deficitirrigated but its leaf growth was similar to $\mathrm{C}$ and $\mathrm{L}$ that were fully irrigated. This may be attributed to the acclimation mechanisms due to R's stress history in Phase 1. Differences in the percentage of ending shoots between treatments also illustrate the sensitivity of vegetative growth to water stress, particularly in Phase 2 .

Upon rewatering, $\mathrm{R}$ showed more rapid recovery of mean daily water use than L. Photosynthetic rate was also higher in $\mathrm{R}$ than in L (Fig. 3A) over the same period that total water use was higher (Fig. 6). These findings are again indicative of acclimation to a history of water stress in R. However, a higher water use in R, compared with L, also led to lower values of $\psi_{1}$ (Fig. 2B) and RWC at the end of Phase 2. Acclimation of R led to a growth advantage over L (Fig. 5), but this advantage could not be sustained over a long period because of the lower values of water status being developed in $\mathrm{R}$.

Contrary to some published research for $A$. deliciosa, $A$. chinensis appears to have good stomatal control, which reduces transpiration if exposed to water stress. Minimum $\psi_{1}$ during Phase 2 was $-1.5 \mathrm{MPa}$ compared with -2.5 to $-3.0 \mathrm{MPa}$ for apple (Malus $\times$ domestica Borkh.) under similar circumstances (Mills et al., 1996). Values of Pn did not decrease with reduced irrigation until a low $\mathrm{g}_{\mathrm{s}}$ of $0.1 \mathrm{~mol} \cdot \mathrm{m}^{-2} \cdot \mathrm{s}^{-1}$ was reached. In Phase 1, a significant drop in $\mathrm{Pn}$ in $\mathrm{E}$ vines lagged behind the significant drop in $\mathrm{g}_{\mathrm{s}}$ and $\psi_{1}$. Elevated leaf temperatures as a result of reduced transpiration or due to hot conditions in the glasshouse reduced $\mathrm{Pn}$ in reduced irrigation vines. The recovery of $\psi_{1}$ and $\mathrm{Pn}$ appeared coupled following rewatering of the reduced irrigation vines. However, $g_{s}$ and $C_{i}$ showed a delay in recovery. Previous reports suggest that osmotic adjustment occurs in A. deliciosa. Our data were only suggestive of osmotic adjustment in $A$. chinensis. Compared with plants undergoing water stress for the first time, a history of water stress resulted in higher Pn, $g_{s}$, water use, and leaf growth. However, lower $\psi_{1}$ and RWC also resulted. The advantages of a stress history were sustained only for a few days. Our plants were growing in pots in a glasshouse during a hot summer so that we were able to impose a level of water deficit that allowed us to approach the physiological limits of gold kiwifruit under reduced irrigation. We may expect that in field conditions, where the extensive root system of established vines explores larger volumes of the soil and ambient temperatures are not so high, the severity of water stress would be less and vine performance better.

\section{Literature Cited}

Barrs, H.D. and P.E. Weatherley. 1962. A re-examination of the relative turgidity technique for estimating water deficits in leaves. Aust. J. Biol. Sci. 15:413-428.

Bunce, J.A. 2007. Low carbon dioxide concentrations can reverse stomatal closure during water stress. Physiol. Plant. 130:552-559.

Buwalda, J.G. and G.S. Smith. 1990. Acquisition and utilization of carbon, mineral nutrients, and water by the kiwifruit vine. Hort. Rev. (Amer. Soc. Hort. Sci.) 12:307-347.

Chartzoulakis, K., B. Noitsakis, and I. Therios. 1993. Photosynthesis, plant growth and dry matter distribution in kiwifruit as influenced by water deficits. Irrig. Sci. 14:1-5.

Chartzoulakis, K., I. Therios, and B. Noitsakia. 1997. The effect of soil water deficit on internal water relations of kiwifruit. Acta Hort. 444:305-310.

Farquhar, G.D., J.R. Ehleringer, and K.T. Hubick. 1989. Carbon isotope discrimination and photosynthesis. Annu. Rev. Plant Physiol. Plant Mol. Biol. 40:503-537.

Green, S.R., K.G. McNaughton, and B.E. Clothier. 1989. Observations of night-time water use in kiwifruit vines and apple trees. Agr. For. Meteorol. 48:251-261.

Gucci, R., R. Massai, and C. Xiloyannis. 1997. Mechanisms of drought avoidance in kiwifruit vines. Acta Hort. 444:312-315.

Gucci, R., R. Massai, D. Piccotino, and C. Xiloyannis. 1993. Gas exchange characteristics and water relations of kiwifruit during drought cycles. Acta Hort. 335:213-218.

Hsiao, T.C. 1973. Plant responses to water stress. Annu. Rev. Plant Physiol. 24:519-570.

Judd, M.J., K.J. McAneney, and K.S. Wilson. 1989. Influence of water stress on kiwifruit growth. Irrig. Sci. 10:303-311.

Kitajima, K., S.S. Mulkey, and S.J. Wright. 1997. Decline of photosynthetic capacity with leaf age in relation to leaf longevities for five tropical canopy tree species. Amer. J. Bot. 84:702-708.

Lakso, A.N. 1990. Interactions of physiology with multiple environmental stresses in horticultural crops. HortScience 25:1365-1369.

Miller, S.A., G.S. Smith, H.L. Boldingh, and A. Johansson. 1998. Effects of water stress on fruit quality attributes of kiwifruit. Ann. Bot. (Lond.) 81:73-81.

Mills, T.M., M.H. Behboudian, and B.E. Clothier. 1996. Water relations, growth and the composition of 'Braeburn' apple fruit under deficit irrigation. J. Amer. Soc. Hort. Sci. 121:286-291.

Mills, T.M., M.H. Behboudian, and B.E. Clothier. 1997. The diurnal and seasonal water relations, and composition, of 'Braeburn' apple fruit under reduced plant water status. Plant Sci. 126:145-154.

Mills, T.M., M.H. Behboudian, and B.E. Clothier. 1998. Discrimination against ${ }^{13} \mathrm{C}$ in water-stressed apple leaves. J. Plant Physiol. 153:237-239.

Reid, J.B., D.W. Brash, I.B. Sorensen, and B. Bycroft. 1996. Improvement in kiwifruit storage life caused by withholding earlyseason irrigation. N.Z. J. Hort. Sci. 24:21-28. 